\title{
A DiNÂMICA DE DESIGUALDADES E INTERSECCIONALIDADES NO TRABALHO DE MULHERES DA LIMPEZA PÚBLICA URBANA: O CASO DAS GARIS ${ }^{1}$
}

\author{
LOURDES Maria BANDEIRA \\ TÂNia Mara Campos de Almeida²
}

\begin{abstract}
Resumo
As características históricas do estado-nação brasileiro, a formação étnico-racial do seu povo e a modelagem da sociedade nos parâmetros modernos trouxeram particularidades às categorias sócio-profissionais. Algumas possuem distinções singulares entre homens e mulheres, são majoritariamente constituídas por grupos negros (pretos e pardos) com baixa escolaridade, respondem a fluxos migratórios internos no país, não acenam com ascensão social, têm direitos trabalhistas reduzidos e, por fim, são invisibilizadas socialmente. Ao mesmo tempo, estão ausentes das estatísticas econômicas, subsumidas das políticas de desenvolvimento e são pouco estudadas pela academia. Este texto é parte dos resultados da investigação sociológica sobre a categoria profissional "mulheres garis" (varredoras das ruas) do Distrito Federal (DF, Brasil). O texto analisa, a partir de dinâmicas e condições interseccionais de um ofício considerado abjeto e desvalorizado da perspectiva socioeconomicamente, profundas desigualdades com consequências diretas sobre as próprias trabalhadoras e as estruturas do mundo do trabalho.
\end{abstract}

Palavras-chave: Interseccionalidade. Desigualdade. Gênero. Raça. Trabalho.

1 A pesquisa com mulheres garis no DF foi realizada a partir do Programa de Iniciação Científica, do Conselho Nacional de Desenvolvimento Científico e Tecnológico (ProIC - CNPq), e vinculada ao projeto de pesquisa "Trabalhadoras Invisibilizadas - trabalho, cidadania, saúde, educação e violência", aprovado pelo Edital MCT/CNPq/SPM-PR/ MDANo. 020/2010.Seleção pública de propostas para pesquisas em temas de Relações de Gênero, Mulheres e Feminismo. Coordenado pela Profa Tânia Mara de Almeida, e este, por sua vez, orientado pela Profa Lourdes Maria Bandeira. Dela participaram como bolsistas os estudantes de graduação em Ciências Sociais: Barbara Stephany de Souza Silva, Jessica Fernanda Albuquerque, Julia Brussi e Rodolfo Godoi.

2 Professoras do Departamento de Sociologia da Universidade de Brasília - UnB, Brasil. e integrantes do Núcleo de Estudos e Pesquisas sobre Mulher - NEPeM/UnB, Brasil. lourdesmbandeira@yahoo.com.br e taniamaraunb@gmail.com 


\title{
THE DYNAMICS OF INEQUALITY AND INTERSECTIONALITIES OF THE WORKING WOMEN OF URBAN HOUSEHOLD WASTE: THE CASE OF STREET SWEEPERS
}

\begin{abstract}
This text is part of the results of the sociological research on the professional category "women street sweepers" of the Brazilian Federal District (DF, Brazil). The paper analyzes a job considered vile and devalued in the socio-economic perspective, from an intersectional approach. The conditions of deep inequalities have direct consequences for the workers themselves and the world of work structures. The historical features of the Brazilian nation-state, the ethnic-racial formation of its people and the modeling of society in modern parameters brought particular features to these socio-professional categories, some of which are mostly made of dark skin people with low education, respond to internal migration in the country, have unique distinctions between men and women, do not wave with social mobility, have reduced labor rights and, finally, are socially invisibilized. At the same time, they are absent from economic statistics, subsumed development policies and are little studied by the academy.
\end{abstract}

Key-word: Intersectionalities. Inequality. Gender. Race. Work.

\section{INTRODUÇÃo}

$1 S_{\text {nos remetem ao Discurso sobre a Origem e os Fundamentos da }}^{\text {desigualdades sociais são tão antigas e persistentes que }}$ Desigualdade entre os Homens, publicado por Rousseau em 1750. Um dos princípios desenvolvidos na obra indica que as desigualdades tendem a se acumular. Tal tendência ainda se mantém nos dias atuais, salvo que, somadas às desigualdades propugnadas por Rousseau, sabe-se que muitas delas se centram na superioridade genérica masculina sobre o sujeito feminino. Pesquisas das últimas décadas evidenciam que, no século XXI, há fatores complexos e múltiplos que implicam em intersecções geradoras de poder, violências e exclusões. Estas estratificam grupos sociais, estabelecendo iniquidades, sobretudo, pela 
condição de gênero, raça/cor, nos grupos mais vulneráveis, inclusive aqueles constituídos no mundo do trabalho.

A discussão sobre "mulher(es) e trabalho" tem pautado os estudos feministas e de gênero, havendo hoje uma extensa bibliografia a respeito no Brasil e exterior ${ }^{3}$, a qual remete, de imediato, a se pensar na triangulação das intersecções características de tal relação: sexo/ gênero, raça e classe social. Ademais, acentua Hirata (2014, p. 61) que "nessa perspectiva a ideia de um ponto de vista próprio à experiência e ao lugar que as mulheres ocupam cede lugar à ideia de um ponto de vista próprio à experiência da conjunção das relações de poder de sexo, de raça, de classe, o que torna ainda mais complexa a noção mesma de 'conhecimento situado', pois a posição de poder nas relações de classe e de sexo, ou nas relações de raça e de sexo, por exemplo, podem ser dissimétricas".

Sem dúvida, há dissimetrias, dependendo de que categoria se está considerando, assim como do "status" que ocupa na estrutura do trabalho. A ela, se acrescentam outras categorias que atuam na dinâmica de relações interseccionalizadas no sentido de que a ideia da intersecção, introduzida por Kimberlé Crenshaw, jurista afroamericana, enfatiza a existência de vários eixos de desigualdades. Além das mais 'usuais' - raça, etnia, gênero e sexualidades -, acrescentouse a condição religiosa, regional, geracional e profissional, abrindo-se a tantas outras para se identificar múltiplas intersecções. Todas, em certa medida, podem estar presentes, constituindo-se um complexo de relações de poder e não apenas um "somatório" a verticalizar as desigualdades. Por sua vez, algumas categorias manifestam-se de modo independente em certas circunstancias (CRENSHAW, 2002).

Dentre as referências, se destacam: Abreu (1995); Almeida et al. (2010); Araújo e Scalon (2005); Bandeira e Almeida (2005); Bandeira e Oliveira (1998); Bruschini (1995); Bruschini e Sorj (1994); CEPAL (1997); Revista Estudos Feministas (1994); Hirata e Kergoat (1997); Küchemann (2001); Küchemann (2008); Melo e Castilho (2009); Melo, Considera e Sabato (2007); Rico (1996); Yannoulas (2005), dentre outras. 
Assim, a interseccionalidade torna-se uma estratégia epistemológica da autora para "levar em conta as inúmeras fontes da identidade, embora não tenha a pretensão de propor uma nova teoria globalizante da identidade" (CRENSHAW apud HIRATA, 2014, p. 62).

No Brasil, interseccionalidades emergem por meio da permanência de traços estruturais do passado escravista no processo de construção da sociedade capitalista, onde a mão de obra feminina escrava, que respondia pelo trabalho desqualificado, braçal e abjeto, reaparece ressignificada no grupo profissional em pauta: as garis ${ }^{4}$. A invisibilidade do trabalho das garis pode ser comparada à invisibilidade do trabalho doméstico. Este é um tipo de serviço que recebe, por adjetivos, ser infindável, repetitivo e improdutivo. Assim que uma tarefa termina outra tem que começar e, logo depois, se volta à anterior. A louça na pia parece nunca acabar, há roupa suja todos os dias, o chão limpo de manhã está sujo à tarde e a poeira jamais cessa em se acumular. Socialmente, as garis desempenham tarefas ligadas ao cuidado, limpeza, higiene que são ainda atribuídas ao fazer feminino, já que a docilidade, paciência e resistência para trabalhos monótonos e repetitivos são qualidades pretensamente consideradas 'naturais' à mulher.

Este forte legado interseccional, deixado pela herança da escravidão, ditou os parâmetros gerais da reprodução do trabalho livre na nossa ordem moderna, tanto que a recente Proposta de Emenda Constitucional, "PEC das Domésticas" (2013), regrou direitos trabalhistas às trabalhadoras domésticas. Única categoria profissional que não os tinha e que é composta por dois terços de mulheres negras (pretas e pardas), pobres e com baixa escolaridade ${ }^{5}$. É exatamente,

\footnotetext{
$4 \quad$ "Gari" é uma referência a Aleixo Gary, fundador de antiga empresa responsável pela limpeza das ruas da cidade do Rio de Janeiro. Aos poucos, a população carioca associou o sobrenome de Aleixo Gary aos/às seus/suas trabalhadores/as e tal denominação se espalhou pelo país.

5 A categoria de trabalhadoras domésticas foi deixada de fora da lei antiga de 1942, presente na CLT - Consolidação das Leis do Trabalho, bem como da Constituição Federal de 1988.
} 
portanto, nas dinâmicas das intersecções que se busca explicar as desigualdades existentes no universo feminino, por exemplo, o limitado acesso a empregos menos precários, rendas salariais altas, vida sem violência, presença em postos de comando e decisão.

Ao pesquisar as garis, é de nosso interesse compreender quais caraterísticas interseccionais e desiguais participam da formação de suas identidades sociais e políticas, bem como de suas subjetividades, tornando-as mais vulneráveis em torno dos seus direitos humanos, na perspectiva de gênero e raça, bem como dos seus direitos trabalhistas. Afinal, a "multiplicidade de diferenciações" contribuiu com o pensamento crítico feminista, trazendo, a partir dos anos 1990, a articulação da perspectiva de gênero com os marcadores sociais que adquirem conotações distintas no que se "[...] refere à conceptualização das diferenças, das maneiras como o poder opera e das margens de agência (agency) concedidos aos sujeitos em distintas abordagens teóricas as diferentes dinâmicas sociais" (PISCITELLI, 2008, p. 264).

\section{A PESQuisa: trabalhadoras Garis ${ }^{6}$ NO Distrito FEDERAL}

A pesquisa foi realizada com mulheres garis, abrangendo o Plano Piloto e dez Regiões Administrativas (RAs) do Distrito Federal (DF), com a preocupação de incluir cidades com variadas composições socioeconômicas, urbanas e espaciais ${ }^{7}$. A atividade de limpeza é responsabilidade do Serviço de Limpeza Urbana (SLU), do governo local, mas é executada, majoritariamente, por contrato com o setor terceirizado privado.

\footnotetext{
6 Neste texto, utiliza-se o termo "gari" no feminino, uma vez que a pesquisa se voltou exclusivamente às mulheres, que formam maciçamente o contingente das varredoras de ruas no DF.

7 Foram entrevistadas garis nas seguintes 'RAs': Ceilândia, Guará, Gama, Cruzeiro, Taguatinga, Estrutural, Sobradinho, e Plano Piloto (RA Brasília, que compreende Lagos Norte e Sul, Asas Norte e Sul).
} 
Um questionário estruturado, com perguntas abertas e fechadas, foi aplicado durante o segundo semestre de 2011 e o primeiro de 2012. Foram 150 respondentes durante a jornada de trabalho ${ }^{8}$. Vale lembrar que as empresas terceirizadas, responsáveis pela contratação de trabalhadoras/res para as atividades, à época, tinham um "exército" de aproximadamente 5.000 funcionárias/os, composto por 62\% do sexo feminino. Não se tratou de estudo com amostra estatisticamente representativa, mas de amostra "espontânea", uma vez que, após o contato inicial com as garis, algumas se recusaram a respondê-lo ${ }^{9} \mathrm{e}$ esse número de 150 mostrou-se suficiente devido às recorrências das respostas que emergiram a partir de então. Participaram apenas aquelas que se manifestaram favoráveis e assinaram o "Termo de Consentimento Livre e Esclarecido".

O questionário aplicado compreendeu nove sessões, mas aqui são analisadas as seguintes: i) características sócio-demográficas das garis; ii) as condições de trabalho; iii) as situações de discriminação e violência no espaço de trabalho e a invisibilidade do trabalho; e iv) as expectativas futuras. É, a partir desses aspectos, que a dinâmica das desigualdades e interseccionalidades aqui será evidenciada.

\section{As CARACTERísticas Sócio-Demográficas das garis}

O perfil sócio-demográfico dessas trabalhadoras se constitui por larga maioria auto nominada negra - preta e parda $(80,7 \%)$, enquanto é ínfima a pertença amarela (4\%) e um percentual um pouco maior (15,3\%) de brancas. As diferenças de raça/cor, combinadas com

\footnotetext{
8 Essa escolha deu-se pela inadequação em serem entrevistadas no horário do almoço, já que lhes é o único momento de descanso da jornada, e porque percebeu-se que muitas delas tinham, no contato com a equipe, a possibilidade de pausa em atividade tão desgastante.

9 O questionário é composto pelas sessões: a) identificação; b) local de trabalho; c) características do trabalho; d) condições de moradia e deslocamento; e) trabalho, família e vida pessoal; f) situações de discriminação e violência no trabalho; g) violência doméstica; h) situação de saúde, e, i) expectativas.
} 
gênero, classe e a atividade laboral expressam, de imediato, o (des)valor social, o qual encontra-se na atividade tida como abjeta realizada por essas mulheres negras. As estratificações de gênero e raça/cor, embora distintas, entrelaçam-se desde o passado escravagista, manifestandose na experiência coletiva, individual e se articulando na Modernidade com classe social. Pode-se afirmar que, no país, raça/cor e gênero são sistemas de relações sociais mutuamente constitutivos, organizados em torno de diferenças corporais percebidas e significadas politicamente, não sendo categorias dadas ou fixas.

O estado civil das trabalhadoras é relativamente equilibrado: solteiras (incluídas aí algumas poucas viúvas) são 51\%, enquanto casadas e em união estável são $49 \%$. Das primeiras, $34,6 \%$ vivem com filhos menores. Ou seja, mais de um terço delas respondem sozinhas pela manutenção econômica e afetiva de filhos. A elas, há ainda sobrecarga associada, pois, em torno de $50 \%$ abrigam parentes em suas moradias. Neste cenário, depara-se com famílias monoparentais, o que confirma o tipo de unidades domésticas nesse segmento social e que tem apresentado crescimento significativo. Na Síntese dos Indicadores Sociais (IBGE, 2012), os dados sobre a distribuição por sexo da pessoa de referência no lar, entre 1998 e 2008, evidencia que houve um aumento importante de mulheres nessa condição: de 25,9\% passa para $34,9 \%$.

Outro cruzamento do perfil pode ser feito com o grau de escolaridade. Um quarto das garis (25\%) tem escolaridade na faixa da $1^{\text {a }}$ a $4^{4^{\mathrm{a}}}$ série e $64,6 \%$ está na faixa de $5^{\mathrm{a}}$ a $8^{\mathrm{a}}$ série do primeiro grau. Essa situação as direciona ao mercado de trabalho em profissões braçais. Chama a atenção que, apenas em 2003, a inclusão de grupos negros no sistema educacional conseguiu aproximar-se, de maneira ainda insuficiente, das metas governamentais. Ou seja, quando da promulgação da Lei no 10.639 , incorporada à Lei de Diretrizes e Bases, a qual instituiu a obrigatoriedade do ensino da história afro-brasileira 
nas escolas do país (QUERINO et al., 2011, p. 131). Nessa direção, evidencia-se como há uma série de outras categorias subsumidas que interferem, diretamente, na geração de desigualdades. O panorama da educação é um bom exemplo, na medida em que o próprio sistema educacional, em sua institucionalidade, já é por si só excludente.

Uma curiosidade da pesquisa foi identificar a presença de mulheres de três gerações de uma mesma família. Todas engajadas na mesma atividade de varrição. No aspecto geracional, então, foram identificadas jovens com menos de 20 anos, embora a maior concentração esteja na faixa etária de 20 a 40 anos (68,6\%); sendo que de 41 a mais de 60 anos estão $41,4 \%$. Ainda, 50,6\% se dizem católicas, enquanto as demais se distribuem em outros grupos religiosos, com predominância de evangélicas.

As garis, na sua grande maioria (92\%), recebem um salário mínimo por mês, acrescido de vale transporte e encargos sociais obrigatórios. A relação interseccional entre classe social, gênero e raça permite identificar obstáculos econômicos e socioculturais no acesso a direitos individuais e sociais, como a dificuldade de fazer uso da Justiça do Trabalho e o agravamento das desigualdades quando associadas à pobreza (IPEA, 2011). Outro obstáculo que se observa é a presença do racismo institucional no próprio ambiente laboral em relação ao tratamento das chefias e dos fiscais que controlam diariamente as garis. Nesse sentido, as mulheres negras vivem mais intensamente o preconceito e a discriminação, elevando a situação de vulnerabilidade em que se encontram. Enfim, todas essas desigualdades entre as garis (gênero, raça/cor, renda, nonoparentalidade, escolaridade, etc) repercutem na qualidade de vida delas, como na saúde, habitação, educação, segurança e cultura, bem como repercutem também de modo articulado com as etapas do ciclo de vida - infância, juventude, adulta e velhice. 


\section{A VARrição: AS CONDições de trabalHo das Garis}

As atividades desenvolvidas pelas garis de varrição e limpeza das ruas, praças e vias públicas do DF estão associadas a fazer capina, catação de lixo e de detritos diários. Cuidam para que o lixo não se acumule nas vias e nos bueiros, causando enchentes e permitindo a proliferação de bichos e doenças. A varrição é feita em duplas ou trios a depender da região ou do itinerário. Percorrem de 7 a $10 \mathrm{~km}$ ao dia. Utilizam basicamente um carrinho, vassoura, pá e sacos de lixo. Na catação, não há equipe; ela é realizada individualmente, usandose espeto e sacos de lixo. A pintura e a capina são denominadas por "diversos" e são feitas por equipes contendo mais de 5 trabalhadoras, pintando meios-fios e retirando matos entre as encostas e os terrenos. Parte do lixo é recolhida no carrinho e parte é acumulada e ensacada para, posteriormente, ser recolhida ao caminhão. É importante ressaltar que existe maior número de mulheres nos dois primeiros tipos de trabalho, enquanto, no serviço de coleta ao caminhão, são predominantemente atividades desempenhas por homens, uma vez que a tarefa é considerada "serviço de peso".

A rotina da limpeza, em algumas localidades, ocorre em três turnos de $7 \mathrm{hs}$, o que significa que a rua está sendo limpa durante 21hs: pela manhã, início às 7 horas e término às 15 horas, com 1 hora de almoço. $\mathrm{O}$ segundo turno inicia às 15 horas e se encerra às 21 horas, e o último turno começa às 22 horas e termina às 4 horas da manhã. Como a maioria das trabalhadoras (98\%) reside em localidade diferente da execução do trabalho, é necessário partir de casa por volta de $2 \mathrm{~h}$ s antes do horário de ingresso. As garis com os uniformes laranja colorem o DF. No geral usam luvas, botas/galochas e chapéu. No DF, foi aprovada uma lei para obrigatoriedade de uso do protetor solar fornecido pelo empregador, o que até o momento da pesquisa não ocorria, salvo em 
situações especiais. As mulheres grávidas encontradas desenvolviam as mesmas atividades das demais.

Por ficar longo período andando pelas ruas, não possuem banheiro fixo ou lugar para manterem a higiene pessoal, sobretudo quando estão menstruadas. Onde existem banheiros, como rodoviária, feiras e comércios, em que o acesso se dá de forma mais livre, não encontram problemas tão grandes comparando com aqueles em trechos vazios, com residências apenas ou no turno da noite. São obrigadas a pedir para usar o banheiro em estabelecimentos comerciais ou em portarias de prédios residenciais, e, muitas vezes, recebendo resposta negativa, com nojo e desprezo por elas. Fazem suas necessidades fisiológicas no mato ou apenas em casa, quando retornam. Algumas garis tiveram infecção urinária e outros danos à saúde devido ao longo tempo de espera para usar um banheiro.

A maioria leva consigo água e alimentação próprias e faz as refeições no local de trabalho - um grupo fez de um túmulo no cemitério a mesa de almoço. Como já lembrado, há uma série de elementos e condições que não têm visibilidade, mas que se constituem parte importante das relações sociais e que são desprezadas nas análises interseccionais. A precariedade das condições de higiene pessoal e de alimentação exemplificam as condições subterrâneas, presentes entre as garis, de agravamento das desigualdades.

Os instrumentos de trabalho também são impróprios, tornando a atividade mais difícil e exaustiva; $44 \%$ delas avaliaram como pesado o carrinho e $11 \%$ como muito pesado, o que causa dor no final da jornada diária. É percebido, portanto, que mesmo quando o espaço de trabalho é composto majoritariamente por mulheres, há a inadequação dos equipamentos de trabalho, uma vez que as medidas consideradas universais para esse tipo de ofício tem referência no corpo masculino, causando posturas incorretas, fadiga muscular, entre outros problemas de saúde para as trabalhadoras. Além disso, 
a exposição e o manuseio de lixo e produtos que proporcionam a inalação de várias substâncias desagradáveis, intempéries climáticas, ao longo do tempo, são altamente nocivas.

Também há queixas em relação a acidentes, como atropelamento por motos e veículos. Em alguns casos, há queixas de agressão corporal, como recebimento de objetos jogados sobre elas por parte dos transeuntes e motoristas; lesões por materiais perfurocortantes, como cacos de vidros, pedaços de madeira, ponta de ferro e pregos; de contato com produtos químicos que queimam e biológicos contaminados, etc. Muitas vezes, os prejuízos à saúde só são percebidos quando a situação chega ao limite e o quadro clínico se encontra avançado, trazendo grande incômodo, sequelas ou incapacidade para o trabalho e as tarefas extra laborais. Mas, ao procurarem superiores ou a equipe médica da empresa, encontram descrédito.

Para o desempenho da atividade não há exigência de qualificação específica nem necessidade de uma formação mínima. Embora não haja exigência de capacitação formal, há características menos visíveis que são observadas no momento de contratação: a capacidade física, sendo que algumas candidatas são submetidas à avaliação física. Nesse sentido, a pesquisa informa que 64,7\% delas tem peso a partir de $70 \mathrm{~kg}$, chegando algumas a pesarem mais de $100 \mathrm{kgs}$. Esse dado é um indicador da força física demandada pelo trabalho. Ora, associado a essa variável verifica-se que 49,3\% tem altura a partir de $1,60 \mathrm{~cm}$, sendo que a mais alta tem $1,74 \mathrm{~cm}$. Cruzadas as duas variáveis, observa-se que as garis, no geral, têm peso excessivo se relacionado à altura.

Embora nessas condições desgastantes e insalubres, consideram que ser gari representa uma forma de mobilidade social. Haja vista que a maior parte delas ingressou na esfera do trabalho pela atividade doméstica, seja como diarista, empregada ou cuidadora (51\%), seja como donas de casa (19\%). A menção à mobilidade é 
explicada pela existência de ter um patrão formal e pessoa jurídica - o empregador como uma empresa, assim como ter carteira assinada e os demais direitos trabalhistas, embora reconheçam que a carga de trabalho pode ser mais dura e abjeta.

Para Kristeva (1986), o abjeto é aquilo do que o "eu" deve se liberar para vir a ser realmente um "eu": uma substância fantasmática, alheia ao sujeito, mas bastante íntima a ele, que acaba por produzir-lhe pânico com sua proximidade. $\mathrm{O}$ abjeto aponta para a fragilidade de nossos limites corporais e subjetivos, perturbando nossas identidades e mesmo sistemas, regras, limites e lugares. $\mathrm{O}$ abjeto indica a quase ausência de tolerância em relação ao outro/diferente, assim como indica a presença do impuro e da impureza.

\section{DisCRIMINAÇÃo E VIOLÊNCIA NO TRABALHO E A INVISIBILIDADE DA VARRIÇÃo}

A invisibilidade ou o que se chama de processo de abjeção é o que está presente cotidianamente na vida e no trabalho das garis. Se, por um lado, as atividades desenvolvidas por elas não são reconhecidas nem valorizados, sobretudo por serem identificadas com a sujeira, com o lixo que polui e contamina, por outro, é necessário que esse trabalho seja destinado a um grupo social: ao mais baixo da pirâmide social. Neste caso, mulheres negras, com baixa escolaridade e pertencentes aos segmentos socioeconômicos menos favorecidos. É uma atividade que não se nota quando é feita, mas que incomoda quando não é realizada.

Afinal, segundo Douglas (1976), a higiene e a limpeza passaram a existir como valor da Modernidade e coube às mulheres zelar para que seu contrário, o abjeto e o impuro, não se espalhem, contaminem e poluam. O trabalho feminino está associado a esse lugar simbólico destituído de reconhecimento enquanto trabalho e por se referir aos cuidados e promoção do bem-estar alheio. São reconhecidos como 
ofícios de menor valor socioeconômico, político e histórico, designados tradicionalmente por meros desdobramentos da "essência" feminina, "devoção" e "missão" espontânea das mulheres (ÁVILA, 2009; MOLINIER, 2004; WOLF, 1997). São profissões associadas à ideia de menor esforço intelectual, criação, domínio da tecnologia, formação geral, e, enfim, à ideia de menos produtiva e de mais sujas e abjetas - a exemplo das garis e domésticas.

A maioria das garis (67\%) entende que é 'ruim ser maltratada no trabalho', embora não considere que este seja uma expressão de violência. Por sua vez, a abjeção e a invisibilidade apresentam-se nas suas vidas através de inúmeras formas de violências, sobretudo pela condição de serem naturalizadas para os serviços de limpeza e cuidados, seja nos espaços privados, seja nos públicos. São tidas como sujas por si mesmas, devido à cor/raça associada à pobreza. Por isso, vê-las como abjetas é uma forma de violência, lhes negando uma identidade valorizada e o reconhecimento de sua condição de humanidade.

Paradoxalmente entendem que a violência ocorre no espaço doméstico-familiar, ao serem humilhadas e agredidas pelos companheiros e maridos (67\%); e têm o mesmo sentimento de humilhação pelos transeuntes, que desviam o caminho, atiram coisas, e fazem agressões verbais gratuitas (em especial as que convivem com pessoas bêbadas nas ruas). Também se sentem alijadas de seus direitos pelo empregador e pelo Estado ao não terem acesso a boas condições de trabalho (equipamentos, dispor de água/bebedouros, a higiene, entre outros).

A ideia de articular a perspectiva interseccional, a partir do contexto de relações sociais (KERGOAT, 2012), na trilogia gênero, raça e classe, nos possibilita empreender uma análise mais complexa das relações sociais na esfera do trabalho, em especial na divisão sexual do trabalho para além da divisão entre homens e mulheres. Mas, 
sobretudo, para estabelecer uma estratificação social entre as próprias mulheres. Assim, observa-se que as mulheres negras sofrem tratamento discriminatório durante a jornada de trabalho, tanto pelos cidadãos como pelas chefias masculinas. Percebem que há um tratamento diferenciado destinado a elas, em especial, na presença de colegas homens-garis - estes são menos controlados e exigidos. Registram que há 'mais amizade' entre os homens superiores e homens-garis. Superar as violências presentes no cotidiano do trabalho é uma das expectativas desejadas por elas e afirmam que vão se organizar para demandar melhores condições de trabalho. Todas estas situações e características constituem uma forma de produzir suas subjetividades pela desigualdade, invisibilidade e abjeção.

\section{INTERJOGOS DE DESIGUALDADES E ABJEÇÃo}

O ingresso das mulheres nas relações produtivas sempre foi um fenômeno complexo, com desdobramentos concretos em todas as searas da vida, tanto que tem se tornado objeto investigado por diversas perspectivas teóricas e recortes nas ciências. Tal ingresso vem se realizando a partir de transformações profundas nas subjetividades, nas interações sociais, nas dinâmicas laborais, nos campos jurídicos, econômicos, dentre outros. Constata-se ainda, a permanência de uma significativa gama de desvantagens, opressões e explorações dirigidas às mulheres neste movimento, que vão desde os preconceitos sofridos por estarem "fora" do seu lugar, os salários desiguais aos dos homens nas mesmas funções, os limites impostos a elas para alcançarem o topo de suas carreiras, até o exercício das duplas e triplas jornadas por continuarem responsáveis pelas atividades domésticas e dos cuidados. Em outras palavras, assegurar a autonomia econômica das mulheres, entendendo essa autonomia como parte da condição para o exercício do poder e de decisão sobre suas vidas (SOARES, 2011), tem 
sido duro. Esta forte persistência revela-se no crescimento da força de trabalho feminina nas últimas décadas.

No caso da categoria pesquisada, as garis sofrem as desigualdades por seus vários pertencimentos a posições inferiorizadas na sociedade. Nesse sentido, Crenshaw propõe a subdivisão em duas categorias: a "interseccionalidade estrutural" (a posição das mulheres de cor na intersecção da raça e do gênero e as consequências sobre a experiência da violência conjugal e do estupro, e as formas de resposta a tais violências) e a "interseccionalidade política" (as políticas feministas e as políticas antirracistas que têm como consequência a marginalização da questão da violência em relação às mulheres de cor) (SOARES, 2011, p. 62).

Em relação à desigualdade de gênero, há décadas, Ortner e Whitehead (1981) mostraram que a equivalência entre a masculinidade (e suas atividades correlatas) e o lócus de prestígio social é capaz de contaminar com seu status superior as ações e os campos de atuação que se encontram a cargo dos homens - apesar do caráter não fixo das tarefas ao longo do tempo e através das sociedades. Assim, não são os trabalhos sob a responsabilidade dos homens o que lhes confere sua importância. Os ofícios em si nada dizem. Na verdade, estes ganham distinções dentro da lógica relacional hierárquica, estabelecida pelo predomínio do pensamento binário que polariza o masculino e o feminino, o público e o privado, a cultura e a natureza, trazendo o primeiro termo em posição de destaque e o segundo subordinado a ele. Em suma, os homens éque dotariam de prestígio as tarefas que realizam, fazendo de masculinidade e status qualidades intercambiáveis, bem como reforçariam seu prestígio ao desempenharem exatamente tais atividades já valorizadas no imaginário social, uma vez que os traços masculinos são vistos como positivos. Por isso, o trabalho abjeto, realizado pelas mulheres, é visto como contaminador, o que provoca desprezo, nojo, desvalorização e afastamento da sociedade. 
Se da ótica do gênero há uma polaridade estabelecida entre masculino e feminino, conferindo um prestígio e status superior ao primeiro termo dessa bipolaridade, algo também semelhante ocorre no campo das relações raciais, tendo esta dimensão da vida social especial relevância também na consideração das desigualdades e diferenças. Embora a estruturação das relações raciais no país possua inúmeros matizes, verifica-se uma associação entre algumas profissões e grupos raciais, o que potencializa a sua abjeção. Em geral, esta associação entre profissões e grupos raciais confere ao grupo social identificado como branco as posições de maior prestígio e status e, por outro lado, confere ao grupo identificado como negro as posições de baixo prestígio e menores salários. Assim, as combinações de raça, classe e gênero nas sociedades modernas, especialmente na sociedade brasileira, resultam em desigualdades que requerem um olhar acurado para o seu entendimento e desmonte via políticas públicas e novas perspectivas simbólicas.

Paralelamente, nota-se que haveria um continuum entre os grupos associados a cada pólo dessa estrutura binária. As mulheres e os homens não se estabelecem como massas homogêneas, que apenas se contrapõem e se complementam mutuamente. Diversos subgrupos de mulheres e de homens compõem novas tramas e relações de assimetria entre si, tanto que se observa, por exemplo, a presença de mulheres em condições superiores a outras em determinadas cenas sociais. São inúmeros os interjogos que se realizam no interior e entre cada gênero, a saber, segundo Kergoat (2009, p. 67-68):

Há uma forma particular da divisão social do trabalho que tem dois princípios organizadores: o princípio de separação (existem trabalhos de homens e outros de mulheres) e o princípio da hierarquização (um trabalho de homem "vale" mais que um trabalho de mulher). Esses princípios são válidos para todas as sociedades conhecidas, no tempo 
e no espaço, o que permite segundo alguns (HéritierAugé, 1984), mas não segundo outros (Peyre e Wiels, 1997), afirmar que exitem dessa forma desde o inicio da humanidade. Esses princípios podem ser aplicados graças a um processo específico de legitimação - a ideologia naturalista, que rebaixa o gênero ao sexo biológico, reduz as práticas sociais a "papéis sociais" sexuados e remetem ao destino natural da espécie.

Se os dois princípios (de separação e hierárquico) encontram-se em todas as sociedades conhecidas e são legitimados pela ideologia naturalista, isto não significa, no entanto, que a divisão sexual do trabalho seja um dado imutável. Ao contrário, ela tem inclusive uma incrível plasticidade: suas modalidades concretas variam grandemente no tempo e no espaço, como demonstraram fartamente antropólogos e historiadores.

No Brasil de hoje, o número de brasileiras com maior escolaridade - ensino superior (completo e incompleto) - representa 19,7\% das mulheres ocupadas (PNAD/2008), o que aumentou significativamente em relação a momentos históricos anteriores. No entanto, o quadro ainda é crítico. Haja vista que

[...] a situação de precarização e de pobreza da grande maioria de mulheres excluídas desse percentual representa $15,8 \%$ (PNAD/2008) das ocupadas. São mulheres com baixos rendimentos, sendo que, em 2009, 30,6\% recebem $1 / 2$ salário mínimo e considerando até um salário mínimo tem-se $72,5 \%$ das trabalhadoras domésticas brasileiras (PNAD/2009). Vale destacar que existem 2.5 milhões de mulheres que trabalham sem remuneração (BANDEIRA, 2010, p. 61).

Tais interjogos acabam por criar dissidências entre as próprias mulheres, uma vez que as relações de poder também se deslocam de uma perspectiva vertical para uma direção de horizontalidade. 
Estabelece-se uma outra dialética de costumes, não mais de focalização de conflito entre homens e mulheres, mas de mulheres em relação a outras mulheres, onde umas - com mais posses, passam a depender de outras - duplamente despossuídas.

É essa dinâmica dos interjogos, que várias autoras, especialmente pela perspectiva pós-colonial, vão nomear de complexo de "gênero", assim como vão apontar para a sua reprodução em articulação com outras categorias sociais e em circunstâncias variadas na ordem patriarcal (SEGATO, 2003). Isto também nos irá indicar que algumas mulheres e alguns homens são mais abjetos que outros, de acordo com a cena social em que se inserem. Logo, as intersecções da categoria gênero com outras categorias sociológicas são o acesso para a compreensão de relações de poder que escapam ao habitual jogo "homem X mulher", situando-se na assimetria existente entre mulheres brancas e negras, mulheres urbanas e rurais, mulheres de classes médias e de classe populares, dentre outras.

O ofício das garis tem se tornado cada vez mais feminizado e racializado. Mesmo os poucos trabalhadores homens que aí se encontram são também portadores de signos sociais inferiores quando relacionados a outras hierarquias, uma vez que o ethos da função sobrepõe-se à condição de gênero. Ser homem e ser gari tem sido considerado tão pejorativo, pois há um imaginário a informar que aquele homem para o qual somente "restou" a condição (e não profissão) de lixeiro, seria porque seu valor, sua identidade não é assemelhada aos seus pares. Trata-se de funcionários/as com baixo grau de escolaridade, negros/as oriundos de regiões empobrecidas e que são violentamente ignorados nas interações sociais por demais grupos de pessoas (COSTA, 2002).

Gutierres (2003, p. 23), no texto "Gari, o homem invisível. Como as Pessoas são transformadas em objetos", acentua: 
[...] a distinção de classe social determina a ação social. É um fenômeno de mão dupla, mas de origens diferentes. Um exemplo: enquanto pessoas da classe média não cumprimentam o gari por entenderem que não se trata de uma pessoa e sim de uma função, ele tenta se proteger da violência da invisibilidade não respondendo a um eventual cumprimento [...], é que pessoas passam a ser entendidas como coisas, chegando a ser imperceptíveis.

Enfim, há um grande estigma rotulador de seus/suas integrantes. Afinal, conforme aponta Douglas (1976), o puro e o impuro são fenômenos que transcendem a esfera da assepsia físico-biológica, constituindo marcas que estabelecem coerência cultural, naturalizando e impondo ações. A sujeira está relacionada à desordem, ao perigo, ao erro, à violência e ao anormal, a qual contamina a quem com ela lida ao mesmo tempo em que irá com ela lidar quem já se encaixa nas suas características. Kristeva (1986) acrescenta que, por meio da exclusão e da segregação, determinadas coisas e pessoas são designadas abjetas. Logo, a sociedade arregimenta forças para que os sujeitos abjetos sejam controlados, tenham seus limites claros, sejam contidos e rejeitados, mantidos fora do corpo social cuja identidade dos seus membros é dita pura, limpa e se vê incluída. Para Butler (1990), trata-se de um processo pelo qual os "outros" genderizados, racializados, empobrecidos são transformados por diversas estratégias de desigualdades políticas, simbólicas, discursivas, econômicas em verdadeiro lixo, produzindo a estabilidade e a coerência das identidades hegemônicas justamente nesta diferenciação daqueles/as que são abjetos.

\section{Considerações Finais}

As atribuições de se limpar ambientes públicos e coletivos, que deveriam pautar-se pelas relações de igualdade entre todos/as os/ 
as que neles atuam e circulam, acarretam distinções que precisam ser (re)conhecidas. Estas mulheres trabalhadoras garis, situadas em nossa sociedade por suas diversas marcas corporais e simbólicas (mulheres negras, com baixa escolaridade, solteiras/sós, que constituem famílias monoparentais, etc.) sofrem desigualdades de modo único, persistente e qualitativamente diferente, difícil de serem analisadas a partir de cruzamentos sem considerar seu engajamento na estrutura do trabalho articulada com as dinâmicas inter-relacionadas de gênero, de raça e de classe que o preside.

Pouquíssimos estudos existem sobre essa categoria profissional e, especialmente, dentro da intersecção de desigualdades. Este fato aponta para um lugar desprestigiado academicamente em relação às pesquisas sobre esse grupo social, embora numericamente bastante significativos e presentes na história do país republicano. Em linhas gerais, isso reforça a ideia de sua condição de tema abjeto também para a intelectualidade brasileira. Afinal, a exposição e a clareza sobre o(s) abjeto(s) em nossa sociedade significa realizar a operação de se aproximar dele(s) de alguma maneira, dando testemunho daquilo que é banido traumaticamente, mas precisa ser incorporado de modo equilibrado e reconhecido conscientemente, refazendo a ordem e o sistema. Logo, representar as condições de abjeção pertinentes a esses grupos em trabalhos acadêmicos é uma forma de contribuir para a (re) vinculação deles, capturando-os de modo reflexivo e integrador em uma nova paisagem mental, simbólica e política.

Por isso, apesar dos avanços alcançados na área de "mulher(es) e trabalho", a compreensão de questões referentes às nuances e implicações do recorte ora proposto podem ajudar a elucidar pontos que vêm dificultando a (re)definição, implantação ou implementação de ações e políticas públicas, bem como do aprimoramento da cidadania dessas mulheres. Afinal, o tema exige que se elaborem várias reflexões e atuações multisetoriais e interdisciplinares, capazes de incidir 
diretamente nas estruturas de normas e valores que vêm organizando a nossa realidade social de maneira desigual entre homens e mulheres, bem como entre os próprios homens e as próprias mulheres.

Haja vista que, em momentos de crise econômica, são essas as mulheres de baixa renda e com baixa qualificação profissional que acabam sendo dispensadas de suas funções e tornando-se inativas no mercado de trabalho por não competirem com seus namorados, maridos, companheiros ou irmãos, até mesmo por não terem recursos financeiros suficientes para que ambos possam se apresentar nos locais de oferta de empregos (FONTOURA; GONZALEZ, 2009; OBSERVATÓRIO BRASIL DA IGUALDADE DE GÊNERO, 2009).

Soma-se a essa gama de questões, o fato de a pesquisa se voltar para a capital brasileira, o Distrito Federal. Após cinquenta e cinco anos de instalação da capital do país, que nasceu de fortes ideais modernizadores, de que modo práticas laborais ainda prémodernas ocorrem em seus espaços públicos? Quais as articulações entre os direitos de cidadania e as restrições hierárquicas em cenário que deveria ser exemplar para novas sociabilidades e novos sujeitos políticos ao país? Para tanto, é necessário considerar que elementos preconceituosos, conservadores e arcaicos, que compõem a cultura brasileira patriarcal, orientam frequentemente as práticas e as concepções das autoridades públicas responsáveis por coibir, erradicar e prevenir a eclosão de situações degradantes e indignas às minorias sociais. Logo, pesquisar como a realidade dessas mulheres trabalhadoras se coaduna com tais plataformas modernas e como elas percebem as ações dos/as agentes públicos/as na busca de lhes garantir seus direitos na capital brasileira revela importância e a necessidade de seguirmos por esta investigação. 


\section{REFERÊNCIAS}

ABREU, Alice. América Latina: globalización, género y trabajo. In: TODARO, Rosalba; RODRIGUEZ, Regina (Ed.). El trabajo de las mujeres en el tempo global. Santiago de Chile: Isis Internacional y CEM, 1995.

ALMEIDA, Tânia Mara et al. (Org.). Gênero e feminismos: convergências (in) disciplinares. Brasília: ExLibris, 2010.

ARAÚJO, Clara; SCALON, Celi (Org.). Gênero, família e trabalho no Brasil. Rio de Janeiro: FGV, 2005.

ÁVILA, Maria Betânia. O tempo do trabalho das empregadas domésticas: tensões entre dominação/exploração e resistência. 2009. Doutorado (Sociologia) - Universidade Federal de Pernambuco, Recife, 2009.

BANDEIRA, Lourdes Maria. Importância e motivação do Estado Brasileiro para pesquisas de uso do tempo no campo de gênero. Revista Ecônomica, Rio de Janeiro, v. 12, n. 1, p. 47-63, jun. 2010.

BANDEIRA, Lourdes Maria; ALMEIDA, Tânia Mara. Relações de gênero, violência e assédio moral. Brasília: AGENDE, 2005.

BANDEIRA, Lourdes Maria; OLIVEIRA, Eleonora. Representações de gênero e moralidade na pratica profissional da enfermagem. Revista da Associação Brasileira de Enfermagem, Brasília, v. 51, n. 4, p. 141-166, out./dez. 1998.

BRUSCHINI, Cristina. O trabalho da mulher brasileira nas décadas recentes. In: SEMINÁRIO NACIONAL: POLÍTICAS ECONÔMICAS, POBREZA E TRABALHO, 2., 1995, Brasília, Anais... Brasília: Ipea, 1995 (Série Seminários, 7).

BRUSCHINI, Cristina; SORJ, Bila (Org.). Novos olhares: mulheres e relações de gênero no Brasil. São Paulo: FCC, 1994.

BUTLER, Judith. Gender trouble: feminism and the subversion of identity. New York: Routledge, 1990.

CEPAL, Las mujeres en América Latina y el Caribe em los años noventa: elementos de diagnóstico y propuesta. Série Mujer y Desarrolo, Santiago de Chile, n. 18, 1997.

COSTA, Fernando Braga. Garis: um estudo de psicologia sobre invisibilidade pública. 2002. Dissertação (Mestrado) - Instituto de Psicologia, Universidade de São Paulo, São Paulo, 2002.

CRENSHAW, Kimberlé. Documento para o encontro de especialistas em aspectos da discriminação racial relativos ao gênero. Revista de Estudos Feministas, Florianópolis, ano 10, p.171-188, 1ํㅗ sem. 2002. 
DOUGLAS, Mary. Pureza e perigo. São Paulo: Perspectiva, 1976.

REVISTA ESTUDOS FEMINISTAS. Rio de Janeiro,n. esp. º sem. 1994.

FONTOURA, Natália; GONZALEZ, Roberto. Aumento da participação de mulheres no mercado de trabalho: mudança ou reprodução da desigualdade? Mercado de Trabalho, Brasília, v. 41, p. 21-26, nov. 2009.

GUTIERRES, Marcelo. Gari, o homem invisível. Como pessoas são transformadas em objetos. Boletim USP, São Paulo, n. 1146, mar. 2003.

HIRATA, Helena. Gênero, classe e raça: interseccionalidade e consubstancialidade das relações sociais. Tempo Social: Revista de Sociologida da USP, São Paulo, v. 26, n. 1, p.6173, 2014.

HIRATA, Helena; KERGOAT, Daniele. La división sexual del trabajo: permanência y cambio. Buenos Aires: Asociación Trabajo y Sociedad, Centro de Studios de la Muljer e Piette/Conicet, 1997.

IBGE. Pesquisa Nacional Por Amostra de Domicílios. Síntese de indicadores. 2012. Disponível em: http://www.ibge.gov.br/home/estatistica/populacao/ trabalhoerendimento/pnad2012/ Acessado em 11 de novembro de 2015.

IPEA. Retrato das desigualdades de gênero e raça. Brasília: IPEA, 2011.

KERGOAT, Danièle. Dinâmica e consubstancialidade das relações sociais. Novos Estudos Cebrap, São Paulo, n. 86, p. 93-103, mar. 2012.

KERGOAT, Danièle. Divisão sexual do trabalho e relações sociais de sexo. In: HIRATA, Helena et al. (Org.). Dicionário crítico do feminismo. São Paulo: UNESP, 2009.

KRISTEVA, Julia. The power of horror: an essay on abjection. New York: Columbia University Press, 1986.

KÜCHEMANN, Berlindes Astrid. Estratégias de sobrevivência de mulheres no setor informal urbano. In: KOHLHEPP, Gert (Org.). Brasil: modernização e globalização. Madrid: Iberamericana, 2001.

KÜCHEMANN, Berlindes Astrid. Mulheres no mundo do trabalho: em busca de um modelo de desenvolvimento inclusivo. In: DAL ROSSO, Sadi; FORTES, José Augusto (Org.). Condições de trabalho no limiar do século XXI. Brasília: Época, 2008.

MELO, Hildete; CASTILHO, Marta. Trabalho reprodutivo - quem faz e quanto custa. Revista de Economia Contemporânea, Rio de Janeiro, v. 13, n. 1, p. 135-158, jan./abr. 2009.

MELO, Hildete; CONSIDERA, Cláudio; SABBATO, Alberto. Os afazeres domésticos contam! Economia e Sociedade, Campinas, v. 16, n. 3, p. 435-454, dez. 2007. 
MOLINIER, Pascale. O ódio e o amor, caixa preta do feminismo? uma crítica da ética do devotamento. Psicologia em Revista, Belo Horizonte, v. 10, n. 16, p. 227-242, dez. 2004.

OBSERVATÓRIO BRASIL DA IGUALDADE DE GÊNERO. A crise econômica internacional e os (possíveis) impactos sobre a vida das mulheres. Mercado de Trabalho, Brasília, n. 40, p. 27-35, ago. 2009.

ORTNER, Sherry; WHITEHEAD, Harriet. Accounting for sexual meanings in sexual meanings: the cultural construction of gender and sexuality. Cambridge: Cambridge University Press, 1981.

PISCITELLI, Adriana. Interseccionalidades, categorias de articulação e experiências de migrantes brasileiras, Sociedade e Cultura, Campinas, v. 11, n. 2, p. 263-274, 2008.

QUERINO, Ana Carolina et al. Gênero, raça e educação no Brasil contemporâneo: desafios para a igualdade. In: BONETTI, Aline; ABREU, Maria Aparecida (Org.). Faces da desigualdade de gênero e raça no Brasil. Brasília: IPEA, 2011.

RICO, Nieves. Formación de los recursos humanos femeninos: prioridad del crecimiento y la equidad. Série Mujer y Desarrollo, Santiago de Chile, n. 15, 1996.

SEGATO, Rita Laura. Las estructuras elementales de la violencia: ensayos sobre género entre la antropología, el psicoanálisis y los derechos humanos. Buenos Aires: Prometeo, 2003.

SOARES, Vera. Mulher, autonomia e trabalho. In: SEMINÁRIO AUTONOMIA ECONÔMICA E EMPODERAMENTO DA MULHER, 2011, Rio de Janeiro. Anais... Rio de Janeiro: FUNAG, 2011(mimeo). Disponível em: <http://www.funag.gov.br/biblioteca/ dmdocuments/Autonomia_Ec_Emp_DasMulheres.pdf>. Acesso em: 13 nov. 2015.

WOLF, Virgínia. Kew gardens: o status intelectual da mulher. Um toque feminino na ficção. Profissões para mulheres. Rio de Janeiro: Paz e Terra, 1997.

YANNOULAS, Silvia Cristina. Perspectivas de género y políticas de formación e inserción laboral en América Latina. Buenos Aires: RedEtis, 2005. 